PRECISION OPTICAL

GLASSWORKING 
SPIE Volume 472

\title{
PRECISION OPTICAL GLASSWORKING
}

\begin{abstract}
A manual for the manufacture, testing and design of precision optical components and the training of optical craftsmen
\end{abstract}

\section{W. Zschommler}

English translation by G. K. Sachdev and J. Maxwell of Feinoptik-

Glasbearbeitung (Werkkünde fur den Feinoptiker)

Additional chapters by G. K. Sachdev and J. Maxwell

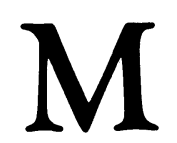

in co-operation with

SPIE

The International Society

for Optical Engineering 
(C) Carl Hanser Verlag Munich Vienna

Willy Zschommler 1963

Title of the original German edition: Feinoptik-Glasbearbeitung (Werkkunde

für den Feinoptiker)

Authorised English language edition, with revisions and additions

(C) English language edition (Part I) and additional chapters (Part II) G. K. Sachdev and J. Maxwell 1984

Softcover reprint of the hardcover 1st edition 1984 978-0-333-35041-6

All rights reserved. No reproduction, copy or transmission of this publication may be made without written permission.

No paragraph of this publication may be reproduced, copied or transmitted save with written permission or in accordance with the provisions of the Copyright Act 1956 (as amended).

Any person who does any unauthorised act in relation to this publication may be liable to criminal prosecution and civil claims for damages.

First published by Macmillan in 1984

Reprinted 1986

Published by

MACMILLAN EDUCATION LTD

Houndmills, Basingstoke, Hampshire RG21 2XS

and London

Companies and representatives

throughout the world

and in the United States of America and Canada by

SPIE - The International Society for Optical Engineering

P.O. Box 10, Bellingham, WA 98227-0010, USA

Typeset by

STYLESET LIMITED

Salisbury, Wiltshire

British Library Cataloguing in Publication Data

Zschommler, W.

Precision optical glassworking.

1. Optical industry

I. Title II. Sachdev, G. K. III. Maxwell, J.

IV. Feinoptik-Glasbearbeitung. English

681'.4 TS513

ISBN 978-1-349-06762-6 ISBN 978-1-349-06760-2 (eBook)

DOI 10.1007/978-1-349-06760-2 


\section{Contents}

Preface to German Edition $\quad x$

Translators' Foreword $\quad x i$

PART I: THE MANUFACTURE OF OPTICAL COMPONENTS 1

Introduction: Optical Components 3

1 Manufacture of Photographic Lenses by the Pitch-pellet Sticking Method (20 operations in accordance with table 1.1) 5

Operation 1: Issue of material 6

Operation 2: Cutting glass blocks into slices 9

Operation 3: Plates to be rough ground to size 10

Milling plates with diamond milling tools $\quad 12$

Operation 4: Marking and cutting plates to size 14

Economised scribing and parting $\quad 14$

Operation 5: Checking cut pieces for bubbles and striae 16

Operation 6: Making stacks of cut pieces for initial rounding 17

Operation 7: Rounding the stack of cut pieces into a cylinder 17

Operation 8: Sticking blanks on the block holder 18

Calculation of radii for block holders and laying-in shells 20

Operation 9: Rough and fine grinding of lenses on block holders 28

The loose abrasive grinding process 29

Correction of grinding shells $\quad 32$

Operation of grinding and polishing machines $\quad 36$

Effects of different adjustments on grinding machines $\quad 39$

Turning and milling of spherical shells $\quad 42$

Smooth grinding with diamond tools $\quad 46$

Operation 10: Polishing lenses on block holders 46

The polishing process $\quad 50$

Operation 11: Unblocking lenses from pelleted block holders 54 
Operation 12: Cleaning the lenses

The automatic cleaning of optical components using ultrasonic cleaning methods

Operation 13: Centration of lenses

Centration by the observation of reflected images 56

Optical centration with transmitted light $\quad 57$

$\begin{array}{ll}\text { Optical centration by autocollimation } & 58\end{array}$

$\begin{array}{ll}\text { The edging of lenses ' } & 58\end{array}$

Accuracy obtainable with optical centration methods 60

Mechanical centration with the bell-clamping method 62

Centring accuracy in the bell-clamping method 64

$\begin{array}{ll}\text { Operation 14: Chamfering of lenses } & 67\end{array}$

Operation 15: Inspection of lenses $\quad 70$

Operation 16: Polishing correction of lenses $\quad 73$

Operation 17: Coating of lenses with reflection-reducing films 75

Antireflection coating as a protection against stain formation $\begin{array}{ll}\text { on polished glass surfaces } & 76\end{array}$

Stain formation on optical glass $\quad 76$

Operation 18: Optical cementing of lenses $\quad 77$

$\begin{array}{ll}\text { Cementing with Canada balsam } & 77\end{array}$

Cold cementing methods $\quad 80$

Operations 19 and 20: Final inspection and pairing of components 81

\section{Manufacture of Photographic Objective Components on Hard Block}

Holders (28 operations in accordance with table 2.1)

Operations 1-9: Preparation of work

Operation 10: Milling witness marks

Operation 11: Sticking lens components on the hard block holders for first side processing

The design of hard block holders

The manufacture of cementing wafers

Operation 12: Milling lens components on hard block holders

The milling of single lenses and blocks of lenses on hard block holders in mass production

Operation 13: Grinding lenses on hard block holders

Automation of the grinding process

Operation 14: Polishing lens components on hard block holders 106

Polishers and polishing media

Operation 15: Protective lacquering and deblocking

Operation 16: Milling or grinding to the required centre thickness

Operation 17: Unblocking and reblocking of lenses on hard block holders

Operations 18-21: Second side processing 


\section{Manufacture of Microscope Lenses} (6 different process descriptions, according to the form of the lenses)

(1) Microscope lenses that may be, or have to be, edged before polishing (with two examples)

(2) Sharp-edged microscope lenses that do not require edging (with two examples)

(3) Microscope lenses where both sides must be individually worked (with an example)

(4) Microscope lenses whose first side may be processed on hard block holders, and whose second side is worked as a single surface (with an example)

(5) Microscope lenses whose first sides are worked individually, and whose second sides are worked on hard block holders (with an example)

(6) Objective front lenses that are made from glass spheres

\section{Manufacture of Objectives for Astronomical Instruments}

\section{Manufacture of Test Plates}

Measuring the radii of test plates

\section{Manufacture of Low-cost Curved Mirrors}

The generation of curves using the method of thermal sagging

\section{Manufacture of Aspheric Surfaces on Lenses}

Numerically controlled aspheric surface cutting using specialist lathes and milling machines

\section{Manufacture of Prisms}

1. Porro prisms of the first type (23 operations in accordance with table 9.1)

Manufacture of Porro prisms of the first type from moulds

Manufacture of Porro prisms by cementing them on supporting jigs 
2. Dove prisms

3. Porro prisms of the second type ( 27 operations in accordance with table 9.2)

4. Pentagonal prisms

Pentagonal prisms of 5 minutes of angular accuracy (14 operations in accordance with table 9.3)

Pentagonal prisms of higher angular accuracy

Pentagonal prisms of the highest accuracy using optical contact tooling (13 operations in accordance with table 9.4)

5. Roof edge prisms

The manufacture of roof edge prisms by hand methods (16 operations in accordance with table 9.5)

The quantity production of roof prisms (11 operations in accordance with table 9.6)

The manufacture of optical contact tooling bars

Mass production methods in optical production engineering

10 Process Materials and Process Control

Loose abrasive smoothing

Diamond smoothing

Measurement and control of surface finish

Polishing rouge

Diamond milling tools

Cooling oil for milling

Polishing pitch

Cements and waxes

PART II: OPTICAL CALCULATIONS, SPECIFICATIONS AND INTERFEROMETRIC TESTING

11 Optical Calculations

Focal length, magnification and lens position

Paraxial raytracing

12 Optical Specifications

(1) Focal length and magnification

(2) Aperture: resolution, working spatial frequency and photometric requirements

(3) Field of view and vignetting

(4) Chromatic bandwidth

(5) Mechanical position and size

(6) Aperture position 
13 Aberrations and Their Correction 266

1. Sperical aberration $\quad 267$

2. Longitudinal chromatic aberration 270

3. Coma 272

4. Transverse chromatic aberration $\quad 275$

5. Astigmatism 276

6. Field curvature 277

7. Distortion 279

14 The Design of Cemented Achromatic Doublets 281

15 Interferometers and Their Applications in Optical Testing 292

The experimental facts and a fundamental example 292

Two beam interferometry 295

Specific interferometers 297

The Fizeau interferometer 297

The Michelson-Twyman-Green interferometers 300

A modification of the Twyman-Green interferometer 304

$\begin{array}{ll}\text { Shearing interferometers } & 305\end{array}$

Common path interferometers 308

The point diffraction interferometer 309

Index 311 


\section{Preface to German Edition}

The original inspiration for this book is to be found in a series of slide lectures describing the manufacture of optical components in America, which were held before audiences of production engineers in Wetzlar in the post-war years of reconstruction.

Compiled for vocational training purposes, this book on the manufacture of optical components, from simple handwork to modern machine finishing, aims to provide the optical worker and the recently qualified engineer engaged in optics with a much needed companion volume to the many books that exist in the fields of theoretical optics and mechanical engineering.

The description of the fundamentals of optical manufacture is intended to perform the same function as technical lectures for beginners and also for qualified engineers who want to set up modern economic optical production and who cannot do so without an understanding of the work processes. It is a peculiarity of optics, in contrast to mechanical manufacture, that very little is published on the actual work processes. Only comparatively few engineers have a knowledge of optical manufacture, for which the necessary training is customarily obtained only by an apprenticeship in the optical trade. It is therefore a further purpose of this book to present this training in a form suitable for the self-tuition of engineers.

For a further understanding of the work processes in optics it is advisable to consult the German national standard of optics manufacture DIN 3140. This contains many practical hints for the testing of optical parts and also guidelines for maintaining optical manufacturing tolerances, with many manufacturing hints and guidelines for the preparation of the optical drawings that are used in modern industry.

Wetzlar, June 1963

Willy Zschommler 


\section{Translators' Foreword}

When students of optics, engineers, apprentices, craftsmen and specialist technicians look for books on optical manufacturing in the English language, they find that very few have ever been published and these are mostly out of print. Even when they do manage to find a copy of one of these books in a technical library or preserved lovingly by one of the older craftsmen, they may find the information they require but they do not find a compact textbook that leads them systematically through the various stages of optical component manufacture.

While young workers in the metal-based industries have a number of good textbooks and a range of well organised courses linked to qualifications and a career structure, the trainee in optical manufacturing usually has no such support, and it is our intention in translating, updating and extending this book to help them in this direction by providing a suitable guide book.

W. Zschommler's book Feinoptik-Glasbearbeitung stands out in the literature as a very complete, compact, logical and graphic account of the principles and details of both traditional and modern methods of glassworking, as followed for both small quantity and large volume manufacturing.

The late Willy Zschommler had an extensive knowledge of the optical industry and much experience as a teacher of young craftsmen. His book is the result of a number of illustrated lectures for craftsmen and engineers in the optical industry, which have been turned into a profusely illustrated manual of optical glassworking. The subject matter is treated in a systematic and logical fashion and it deals with every aspect of optical component manufacture from basic workshop principles to modern high-speed processing methods such as diamond smoothing and polyurethane polishing. The emphasis at all stages of the book is on the development of economic processing methods matched to the required component tolerances, so that the material is also particularly well suited to the needs of production engineers and workshop foremen.

In translating this book we have not only brought the original text up to date but we have also added a second part, which is an introduction to the detailed 
specification of optical systems, optical calculations, lens design and the interferometric testing of optical components and subassemblies. We believe that the modern optical technician requires a greater breadth of knowledge than was formerly the case, to meet the sophisticated demands of modern optical manufacturing. It is hoped that this part of the book will encourage the reader to take advantage of the microelectronic revolution, have a go at simple optical calculations and also make more use of the powerful methods of interferometric testing which are so appropriate to the needs of optical manufacturing.

It now gives us particular pleasure to be able to record our thanks to our respective wives, Raj and Janet, for their patient support during our labours of translation, and also to Mrs Shobha Kumar for her help in preparing the manuscript. We would also like to thank the many senior craftsmen, engineers and technicians, unfortunately too numerous to mention individually, with whom it has been our honour to work over the years and for whose successors this book is intended.

January, 1984

G. K. Sachdev, Dehra Dun, India J. Maxwell, London, England 